1 Secretaria de Estado da Saúde do Paraná (Sesa) PR) - Curitiba (PR), Brasil. yumiemurakami@gmail.com

2 Secretaria de Estado da Saúde do Paraná (Sesa/ PR) - Curitiba (PR), Brasil. nanferpinto@gmail.com

3 Universidade Federal do Paraná (UFPR), Núcleo de Estudos em Saúde Coletiva - Curitiba (PR), Brasil. guilherme.albuquerque. ufpr@gmail.com

4 Universidade Federal do Paraná (UFPR), Núcleo de Estudos em Saúde Coletiva - Curitiba (PR), Brasil. poperna1@gmail.com

5 Universidade Tuiuti do Paraná (UTP) - Curitiba (PR), Brasil.

adriana.lacerda@utp.br

\section{Intoxicação crônica por agrotóxicos em fumicultores}

\author{
Chronic pesticide poisoning in the tobacco farming
}

Yumie Murakami', Nanci Ferreira Pinto 2 , Guilherme Souza Cavalcanti de Albuquerque ${ }^{\mathbf{3}}$, Paulo de Oliveira Perna ${ }^{4}$, Adriana Lacerda 5

RESUMO Este trabalho teve como objetivo pesquisar intoxicações crônicas por agrotóxicos e a relação com o processo de trabalho na fumicultura. A amostra constituiu-se de 46 indivíduos, a respeito dos quais se estudaram, com uma abordagem qualiquantitativa, sinais e sintomas de intoxicação por agrotóxico, modo de vida configurado pela inserção no trabalho e no consumo e sua correlação com o atual modo de produção. Realizaram-se anamnese com detalhamento da história laboral, exame físico e exames complementares. Foram identificados transtornos psiquiátricos menores, perdas auditivas neurosensoriais, polineuropatia tardia induzida por organofosforados, configurando 20 casos de intoxicação crônica.

PALAVRAS-CHAVE Agroquímicos. Envenenamento. Saúde do trabalhador.

ABSTRACT This paper aimed to search chronic poisoning by pesticides and its relation with the process of work in tobacco farming. The sample consisted of 46 individuals, who have been studied, with a quali-quantitative approach, signs and symptoms of intoxications by pesticide, way of life configured by its insertion in the work and the consumption and its correlation with the current means of production. Anamnesis detailing the labor history, physical and complementary exams have been carried out. Minor psychiatric disorders, loss of sensorineural hearing, organophosphate-induced delayed polyneuropathy, configuring over 20 cases of chronical intoxication were identified.

KEYWORDS Agrochemicals. Poisoning. Occupational health. 


\section{Introdução}

A fumicultura, desenvolvida por pequenos proprietários rurais, principalmente no Sul do Brasil, tem repercussões graves sobre a saúde desses trabalhadores.

A indústria do fumo é representada mundialmente por poucas empresas transnacionais, que dominam a produção, o processamento, o beneficiamento e a comercialização do fumo e de seus produtos derivados. Nos últimos anos, com as restrições impostas ao consumo de tabaco nos países desenvolvidos, essas empresas se voltaram para os mercados rentáveis da Ásia e da África, que apresentam crescimento de cerca de $3 \%$ ao ano. A produção, por sua vez, migrou para países como China, Brasil, Índia, Zimbabwe e Indonésia. As empresas desse ramo incentivam países em desenvolvimento e seus agricultores a cultivar o tabaco, como ocorreu no Brasil, atualmente, o segundo maior produtor do mundo (BIOLCHI, 2003).

Em nosso país, tais empresas encontraram condições ótimas: reduzidos custos para a produção, espaços de agricultura não mecanizada, realizada de forma manual e artesanal pelos pequenos agricultores e suas famílias, com consequente aumento da qualidade do produto (BIOLCHI, 2003), além da frouxidão do aparato de leis e normas.

As empresas transnacionais estabelecem um vínculo monopsônico com o produtor, através do Sistema Integrado de Produção do Fumo, exercendo, por meio de contratos, um controle absoluto sobre seu processo de trabalho. Os fumicultores são obrigados a utilizar a tecnologia, as sementes, os fertilizantes e agrotóxicos que lhes são impostos, além de assumir os custos desses meios de trabalho, assim como de estufas, fornos e lenha. Ao final, devem produzir os volumes de fumo estabelecidos nos contratos, sob pena de severas sanções, que podem incluir até o confisco de toda a produção e de bens pessoais.

Embora os fumicultores, em geral, sejam proprietários da terra, o Sistema Integrado constitui uma forma de relação de exploração capital-trabalho, pois não possuem, a princípio, todos os meios de produção, e se submetem a um processo que lhes é imposto pela indústria.

Nos estados do Sul, na safra de 2014/2015, a fumicultura envolveu 153.730 famílias, 409.000 hectares plantados, com colheita de 874.000 toneladas do produto. No estado do Paraná, o cultivo do tabaco está presente em 143 municípios (PARANÁ, 2016B).

O processo de trabalho do cultivo do tabaco impõe, às famílias produtoras, o contato com múltiplos agrotóxicos muito tóxicos - herbicidas, inseticidas, fungicidas e antibrotante -, que devem ser utilizados várias vezes, desde a semeadura, o transplante de mudas, até o crescimento completo da planta.

O Paraná é o terceiro maior consumidor de agrotóxicos do Brasil, com 80 tipos de agrotóxicos liberados para o cultivo do fumo, $56 \%$ deles enquadrados como extremamente tóxicos ou altamente tóxicos (PARANÁ, 2016A).

Dados do Sistema de Informação de Agravos de Notificação (Sinan), do Ministério da Saúde, apresentam, no período de 2007 a 2015, registro médio anual de 740 casos de intoxicação por agrotóxicos no Brasil, sendo 98,7\% deles de intoxicações agudas e 1,3\% crônicas (BRASIL, 2016).

Pesquisa realizada pelo Instituto Brasileiro de Geografia e Estatística (IBGE), intitulada 'Uso de Agrotóxicos no Estado do Paraná: safra 1998/ 1999’, por outro lado, aponta 29.250 intoxicações por agrotóxicos nos anos de 1997 a 1999, com 22.772 atendimentos médico-hospitalares no mesmo período (IBGE, 2001), o que sugere imensa subnotificação desses agravos no Paraná.

Além dos agrotóxicos aos quais se expõem os trabalhadores nas longas e extenuantes jornadas de trabalho, ao final do cultivo, na colheita, na secagem, na manipulação e na classificação das folhas de fumo, os trabalhadores ficam expostos, também, à ação tóxica da nicotina da planta, ocasionando a chamada 'doença da folha verde', com sintomas como náuseas, vômitos, tonturas, confusão mental e tremores. 
Diante do exposto, propôs-se o presente estudo, com o objetivo de pesquisar as intoxicações crônicas por agrotóxicos e a relação com o processo de trabalho na fumicultura, no sentido de dar maior visibilidade à questão e de fornecer subsídios ao planejamento de intervenções de prevenção desses agravos e à promoção da saúde.

\section{Métodos}

Trata-se de um estudo qualiquantitativo cuja amostra foi composta a partir das notificações de intoxicações agudas registradas no município de Rio Azul, estado do Paraná, nos anos de 2000 a 2010, o que totalizou 41 casos.

A pesquisa foi realizada em duas etapas: a primeira consistiu na aplicação de questionário para levantamento de dados socioeconômicos, do processo de trabalho e de exposição a agrotóxicos, preenchido pelos pesquisadores; na segunda etapa, realizou-se avaliação clínica, que consistiu em anamnese, exame físico e aplicação do Self-Reporting Questionnaire (SRQ-20), indicado pela Organização Mundial da Saúde (OMS) como instrumento para abordagem das desordens psiquiátricas menores.

Realizou-se busca ativa desses indivíduos e de seus familiares e contato, em visita domiciliar, para apresentação da pesquisa e convite à participação. $\mathrm{O}$ projeto foi aprovado pelo Comitê de Ética em Pesquisa do Setor de Ciências da Saúde da Universidade Federal do Paraná, em 28 de outubro de 2009, com número 831.166.09.10, e pelo Comitê de Ética em Pesquisa da Secretaria Estadual de Saúde do Paraná (Sesa-PR/HT), sob o parecer $n^{\circ}$ 138/2009, em 03 de dezembro de 2009.

Após assinatura do termo de consentimento livre e esclarecido, 62 participantes responderam a um questionário sobre o processo e as relações de trabalho na fumicultura, inserção na produção e no consumo, bem como problemas de saúde percebidos como advindos dessa atividade. Desse total, 46 pessoas participaram da segunda fase, composta por anamnese e exame físico, aplicação do Self-Reporting Questionnaire (SRQ-20), validado no País em usuários de serviços de saúde da atenção primária (MARI; WILLIAMS, 1986), além de coleta de sangue para realização de exames de: colinesterase eritrocitária e plasmática, hemograma completo com contagem de reticulócitos, ureia, creatinina, proteínas totais e frações, Bilirrubinas totais e frações, fosfatase alcalina, TGO, TGP, GAMA-GT, $\mathrm{TSH}$, glicemia de jejum, colesterol total e frações, triglicerídeos, VRDL.

Realizou-se avaliação audiológica básica e complementar. Os testes usados na avaliação audiológica básica foram audiometria convencional e curva timpanométrica $(n=46)$; na avaliação audiológica complementar, utilizaram-se Emissões Otoacústicas Evocadas por estímulo transiente (EOAT, $\mathrm{n}=16$ ), Randon Gap Detection Test (RGDT, $\mathrm{n}=20$ ) e Potenciais Evocados Auditivos do Tronco Encefálico (Peate, $n=6$ ).

A avaliação básica foi realizada também na Unidade Básica de Saúde de Rio Azul em cabina audiométrica, um audiômetro e um impedanciômetro portáteis.

A avaliação complementar foi realizada na clínica de fonoaudiologia de uma universidade estadual, próxima a Rio Azul, no mesmo dia da avaliação básica para seis participantes, e em outro momento para os demais participantes.

O critério de inclusão para a bateria audiológica complementar foi apresentar média audiométrica de até 25 dBNA nas frequências de 500,1000 e $2000 \mathrm{~Hz}$ e curva audiométrica do tipo A. O número reduzido de participantes na bateria complementar se deu, primeiramente, devido aos critérios de inclusão e também pela dificuldade de deslocamento dos participantes até a clínica universitária em data posterior à avaliação audiológica básica.

$\mathrm{Na}$ avaliação dos casos de intoxicação, foram considerados: processos e cargas de trabalho; exposição a agrotóxicos; dados epidemiológicos do território do grupo de 
exposição; histórico das intoxicações agudas prévias e sua gravidade (conhecimento sobre a natureza do agente tóxico, tempo e forma de manipulação), além dos dados de anamnese dirigidos à caracterização do quadro clínico.

Casos sugestivos de polineuropatia tardia induzida por organofosforado foram avaliados por neurologista para a confirmação diagnóstica.

Os participantes que apresentaram alterações sugestivas de complicações foram encaminhados para avaliação e atendimento junto ao Sistema Único de Saúde (SUS). Cada participante recebeu um laudo da avaliação realizada, bem como os resultados dos exames.

\section{Resultados e discussão}

\section{Características sociais, econômicas e ambientais}

Das 62 pessoas que responderam ao questionário, $55 \%$ eram do sexo masculino, a maioria na faixa etária de 19 a 59 anos. Quanto à escolaridade, $75,7 \%$ cursaram até a quarta série do Ensino Fundamental. Essas características são semelhantes às informações encontradas pela Pesquisa Nacional por Amostra de Domicílios com relação ao perfil da população rural economicamente ativa: $71 \%$ dessa população têm menos de 50 anos, e $75 \%$ apresentavam menos de 10 anos de estudo (IBGE, 2013).

A maioria das propriedades é de pequeno porte, com área de um a oito alqueires. Em geral, na cadeia produtiva do fumo, os produtores são pequenos proprietários ou arrendatários (ALMEIDA, 2005). Quanto à estrutura das propriedades, $95 \%$ possuem luz elétrica, e apenas $16 \%$ possuem abastecimento público de água, enquanto o restante utiliza água de poço, mina ou fonte.

A renda familiar mensal para 61,4\% é inferior a dois salários mínimos, e 60\% recebem auxílio do Bolsa Família. Bonato (2009), em diagnóstico sobre a realidade dos agricultores familiares em regiões de cultivo de fumo, identificou três grupos de produtores de fumo segundo a renda: $37,9 \%$ com renda baixa, insuficiente para a manutenção da família; 33,9\% com renda média, suficiente para a sobrevivência das famílias; e $28,3 \%$ com renda boa, que permite melhores condições de vida.

No mesmo estudo, Bonato (2009) demonstrou que as principais regiões produtoras de fumo no Sul do Brasil apresentaram Índice de Desenvolvimento Humano (IDH) abaixo da média estadual, nos três estados da região Sul. Apontou, também, que onde se planta fumo, os indicadores de frequência escolar e renda são sempre menores. No presente estudo, identificou-se absenteísmo das crianças e adolescentes em função do trabalho ou de sintomas de intoxicação, além de dificuldade de aprendizagem e alto índice de repetência.

Nesta pesquisa, $58 \%$ dos participantes ainda plantavam tabaco, os demais já haviam mudado de atividade. Para 55\% daqueles, a permanência na fumicultura, já superior a 20 anos, era motivada pela garantia de compra do produto pela indústria fumageira.

\section{O processo de trabalho na fumicultu- ra e a exposição a agrotóxicos}

O trabalho é, antes de tudo, um processo entre o homem e a natureza, processo este em que o homem, por sua própria ação, medeia, regula e controla seu metabolismo com a natureza. Ele se confronta com a matéria natural como com uma potência natural [Naturmacht]. A fim de se apropriar da matéria natural de uma forma útil para sua própria vida, ele põe em movimento as forças naturais pertencentes a sua corporeidade: seus braços e pernas, cabeça e mãos. (MARX, 2013, P. 654).

Para Marx,

os momentos simples do processo de trabalho são, em primeiro lugar, a atividade orientada a um fim, ou o trabalho propriamente dito; em 
segundo lugar, seu objeto e, em terceiro, seus meios. (MARX, 2013, P. 655-656).

O trabalho é a utilização da força de trabalho, e o meio de trabalho é aquilo que o trabalhador interpõe entre si e o objeto do trabalho e que lhe serve de guia de sua atividade sobre esse objeto (MARX, 2013, P. 658).

O tabaco é um produto agrícola obtido a partir das folhas de plantas do gênero 'Nicotiana'. No processo de trabalho para a sua produção, os agricultores têm como objetos, portanto, a própria planta 'Nicotiana tabacum', a terra, a água e a madeira que retiram da natureza e transformam em lenha para a secagem das folhas.

Como meios de trabalho, os fumicultores utilizam, na maioria das vezes, equipamentos agrícolas rudimentares, como arado de tração animal, enxadas, cestos, carroças, facão, pulverizadores costais, fornos à lenha, entre outros.

O processo de trabalho para o cultivo do fumo e a produção do tabaco inclui atividades de preparo da terra, semeadura dos canteiros, transplante de mudas, tratos culturais, colheita e capação, secagem e confecção de 'bonecas' das folhas.

O uso da mão de obra familiar nessa cadeia produtiva é imperativo para o alcance da produtividade exigida pela empresa (BONATO, 2009; ALMEIDA, 2005), inclusive com o trabalho de crianças e adolescentes.

A jornada de trabalho das famílias entrevistadas variava de acordo com as tarefas necessárias em cada fase do cultivo, sendo, em geral, prolongada. Nos períodos de secagem do fumo e confecção de bonecas, a jornada se torna mais intensa e extensa, com realização de trabalho noturno para a alimentação ininterrupta do forno da estufa com lenha.

A maioria das tarefas era realizada manualmente, com exigência de grande esforço físico, coincidindo com os achados de Biolchi (2003).

Esse modelo produtivo impõe o uso de diversos agrotóxicos, fator que torna mais complexo o diagnóstico das intoxicações
(MATOS; SANTANA; NOBRE, 2002; OPAS/OMS, 1996). No presente estudo, por meio da análise das respostas dos questionários, evidenciou-se o contato dos fumicultores com múltiplos agrotóxicos de alta toxicidade, aplicados, em geral, com equipamento costal e sem assistência técnica.

Os trabalhadores avaliados tiveram contato com inseticidas: organofosforados (83\%), carbamatos (63\%), piretroides $(76 \%)$ e neonicotinoides (78\%); fungicidas: ditiocarbamato (76\%) e outros fungicidas $(63 \%)$; herbicidas: glifosato (52\%), dinitroanilina $(52 \%)$ e outros herbicidas (73\%); e fumigantes, como o brometo de metila (39\%), entre outros, na maioria dos casos, por períodos de mais de 10 anos.

Há muitas lacunas no conhecimento sobre a exposição combinada a agrotóxicos. Os estudos de toxicidade avaliam apenas a exposição a um ingrediente ativo isolado em animais de laboratório, com uma única via de exposição. No trabalho agrícola, porém, ocorrem exposições combinadas ou multiexposição a agrotóxicos.

A lógica dominante na medicina reconhece que muitas doenças e agravos em agricultores que manipulam agrotóxicos costumam resultar da exposição a tais substâncias, chamando a isso de 'fator de risco'. Assim, escolhido um fator - entre tantos que, como exposto acima, compõem o processo produtivo e estão implicados na produção dos agravos -, ele será elevado à categoria de elemento causal, desconsiderando todo o peso determinante da estrutura produtiva. Esse raciocínio causalista esconde o fato de que as pessoas têm muito pouca liberdade em seus 'estilos de vida' para se proteger dos processos destrutivos impostos pelo modo de vida no qual os fumicultores são praticamente obrigados a viver.

Segundo Breilh (2006), a lógica na qual se inscrevem as atividades agrícolas convencionais vai determinar um desfecho inexorável para os trabalhadores envolvidos, pois a exposição de um indivíduo não é isolada nem uma 'simples contingência', mas está inscrita 
num padrão de intoxicação que, por sua vez, adquire sua forma e sua contundência epidemiológica no seio de um modo de vida grupal. Para o referido autor, trata-se de uma situação em que seria mais apropriado falar em 'imposição' de um modelo de processo produtivo aos trabalhadores - que determina seus estados de adoecimento ou agravamento - do que 'exposição' a um ou mais fatores de risco que podem ser localizados como agentes causadores.

Além dos agrotóxicos, o cultivo do fumo também impõe o contato intenso com a nicotina presente nas folhas manuseadas em várias fases do processo produtivo.

Apesar de inadequados e insuficientes para a proteção dos trabalhadores, os Equipamentos de Proteção Individual (EPI) eram utilizados apenas por $50 \%$ dos entrevistados, que, mesmo assim, faziam uso somente de parte das peças dos mesmos.

\section{Relações assimétricas dos trabalha- dores com o capital}

O modo de vida desse segmento de trabalhadores é marcado por intensa fragilização frente às empresas fumageiras. Essas impõem aos produtores o chamado 'Sistema Integrado', com suposta garantia da compra do produto e assistência técnica.

Se, por um lado, a relação com as empresas garante a compra do produto, por outro, impõe aos fumicultores condições muito adversas, retirando, por exemplo, a autonomia para definir quanto e como produzir, o preço e a escolha do comprador.

Mais de $30 \%$ dos entrevistados referiram a existência de uma dívida junto à empresa, além de já terem sofrido algum tipo de sanção pela impossibilidade do cumprimento de metas que aquela lhes impõe. Quase a metade deles gostaria de livrar-se do cultivo do fumo, mas não o faz pela falta de alternativa de produção de gêneros com garantia de comercialização.

As amarras contratuais são decorrentes da imposição de um pacote tecnológico (sementes, agrotóxicos, fertilizantes, utensílios, equipamentos de proteção individual, assistência técnica gratuita, transporte da safra etc.), do controle rígido dos ganhos dos fumicultores - através da definição antecipada dos preços pagos e da meta de volume de produção - e do impedimento dos agricultores de vender para outros compradores por preçOs melhores (BONATO, 2009).

Constatou-se que os fumicultores encontram dificuldades de financiamento para suas atividades, advindas da insuficiência de políticas públicas de financiamento para os pequenos agricultores. De fato, o Estado brasileiro tem destinado mais recursos ao agronegócio do que aos produtores familiares: enquanto o Programa de Fortalecimento da Agricultura Familiar (Pronaf) recebeu, em 2014, um orçamento de 21 bilhões de reais, o agronegócio contou com valores que chegaram à casa dos 156 bilhões (RIGON; BEZERRA, 2014).

Em geral, nos casos em que os fumicultores necessitam de financiamento, não conseguem manter contato direto com os bancos, sendo intermediados pelas empresas fumageiras, que atuam como avalistas dos seus 'integrados' (assim qualificados pelas próprias empresas) nos ditos financiamentos. Análise realizada por Bonato, Zotti e Angelis $(2010$, P. 56) aponta que um dos problemas verificados no processo de financiamento é que

as empresas não costumam fornecer cópia do documento do crédito gerado aos fumicultores, onde constam as informações sobre as operações realizadas, o que acaba gerando dúvidas e insegurança por parte dos agricultores.

Esse processo de financiamento acaba gerando um endividamento que mantém os fumicultores vinculados às empresas para as safras futuras (ALMEIDA, 2005). No presente estudo, os entrevistados referiram viver uma situação de pressão sobre toda a família, expressa em suas palavras como "vivemos com uma espada sobre a cabeça”, sentimento que, 
segundo seus relatos, já levou fumicultores endividados ao suicídio.

Não existe um empenho efetivo do Estado brasileiro e do Paraná para oferecer outras possibilidades aos agricultores para diversificar a produção, no sentido de superar sua dependência do cultivo do fumo. Apesar de já existirem formulações políticas nesse sentido, há sérios entraves para sua implementação, como a ausência da alocação de recursos financeiros, humanos e a não implementação da reforma agrária (BONATO, 2009).

Apesar dos limites impostos a esses trabalhadores, existem alguns espaços possíveis de reação, entre os quais, seus sindicatos, o Fórum Estadual contra os Agrotóxicos e entidades como a Terra de Direitos, a Via Campesina, o Coletivo Triunfo, o Departamento de Estudos Sócio-Econômicos Rurais (Deser), Assessoria e Serviços a Projetos em Agricultura Alternativa (Aspta), Instituto Guardiões da Natureza, entre outros, bem como ações levadas a cabo por profissionais do setor público, em parceria ou não com as entidades citadas.

Por sua vez, o Ministério Público do Trabalho do Paraná (MTP) também se constitui aliado importante na luta por melhores condições de vida e trabalho de fumicultores. Em 2007, o MPT ajuizou seis ações civis públicas contra as indústrias fumageiras, a Associação dos Fumicultores do Brasil (Afubra) e o Sindicato das Indústrias do Fumo (Sindifumo), devido à existência de trabalho degradante, falta de registro dos trabalhadores e uso de mão de obra infantil (JUSBRASIL, 2007).

Ainda com relação a essa questão, uma ocorrência positiva, em nível nacional, foi a assinatura da Convenção-Quadro, ratificada pelo Brasil em 2005, cujo objetivo é

preservar as gerações presentes e futuras das consequências sanitárias, sociais, ambientais e econômicas do consumo e da exposição à fumaça do tabaco (DESER, 2012),

o que implica a necessidade de os governos implantarem políticas de diversificação, agrícolas e não agrícolas, para os produtores de fumo.

\section{Consequências da exposição laboral aos agrotóxicos}

Há décadas que inúmeros estudos relacionam agravos à saúde humana com a exposição prolongada aos agrotóxicos, entre os quais, o câncer, as doenças neurológicas, hepáticas, renais, respiratórias, imunológicas e endócrinas, as alterações mutagênicas, teratogênicas e genotóxicas.

Em estudos mais recentes, exposição crônica moderada a agrotóxicos mostra maior prevalência de sintomas neurológicos e alterações no desempenho neurocomportamental, como as disfunções cognitiva e psicomotora, além de aumento do risco para a doença de Parkinson (KAMEL; HOPPIN, 2004); aumento de mortalidade e de internações por neoplasias, em municípios com alta exposição aos agrotóxicos, em comparação com municípios com baixa exposição (RIGOTTO ET AL., 2013); alterações no sistema nervoso periférico, glóbulos brancos, fígado e nos eletrólitos de pessoas expostas a piretroides e organofosforados (HU ET AL., 2015).

O uso de agrotóxicos está relacionado ao desenvolvimento de alguns tipos de câncer, como o de cérebro, próstata, rim, linfoma não Hodgkin e leucemia, assim como o aumento do risco de câncer em crianças com exposição pré e pós-natal, filhas de pais expostos no trabalho (BASSIL ET AL., 2007).

Algumas classes de produtos têm sido mais estudadas. Uma delas, os organofosforados, causa efeitos neurotóxicos de forma crônica: distúrbios psiquiátricos, cognitivos e neuropatia periférica (PACHECO-FERREIRA, 2008). A polineuropatia tardia induzida por organofosforado é uma síndrome que ocorre após 7 a 21 dias da exposição a um agrotóxico organofosforado e afeta, predominantemente, nervos longos do sistema nervoso, causando fraqueza simétrica dos músculos periféricos de braços e pernas, com alterações sensoriais 
variáveis. A fosforilação da enzima neuropathy targe esterase é considerada responsável pela disfunção, cuja deficiência pode ser permanente (KAMANYIRE; KARALLIEDDE, 2003).

Os organofosforados podem, ainda, produzir agravos neurocomportamentais, afetando as funções intelectuais, cognitivas, de memória, comportamento, processamento de informações, coordenação motora fina, levando à ansiedade e à irritabilidade (PACHECO-FERREIRA ET AL., 2008).

A utilização prolongada de diferentes agrotóxicos pode ocasionar neuropatias tardias, síndromes neurocomportamentais e distúrbios neuropsiquiátricos, com alta incidência de suicídio, tal como descrito sobre os fumicultores do município de Venâncio Aires (RS) (FALK ET AL., 1996).

Entre fruticultores de Bento Gonçalves (RS), observou-se uma exposição média a 12 agrotóxicos diferentes na safra, que originaram sintomas em diversos sistemas, como o nervoso, o digestivo e o respiratório, além da pele e anexos (FARIA ET AL, 2009).

No presente estudo, como sintomas neuropsiquiátricos referidos, destacaram-se as alterações de humor (52\%), câimbras (39\%), cansaço fácil nas pernas (39\%), fraqueza muscular (35\%), parestesias de membros inferiores (41\%) e superiores (30\%), visão turva (39\%), alteração de sono (33\%), irritabilidade (46\%), diminuição da memória (43\%), tontura (48\%), cefaleia (65\%), sudorese (46\%) e palpitação (33\%).

Estudo realizado com 102 trabalhadores rurais em Nova Friburgo (RJ), para avaliar os efeitos à saúde da exposição múltipla a agrotóxicos, encontrou parestesia em 'bota e luva', cefaleia habitual, astenia, insônia, irritabilidade, visão turva, sensação de peso em membros inferiores, alterações de humor (ARAÚJO ET AL., 2007), resultados muito semelhantes aos encontrados na presente pesquisa para os trabalhadores da fumicultura de Rio Azul.

Estudo de agricultores de Paty do Alferes (RJ) encontrou, como sintomas mais frequentemente relatados, dor de cabeça (71\%), enjoo (50\%), diminuição da visão (38\%), vertigem (35\%), irritação da pele (29\%), perda de apetite (24\%), tremores (15\%), vômitos $(15 \%)$, crise alérgica (6\%), diarreia (6\%), dores no peito (6\%), secura na garganta (3\%) e nervosismo (3\%) (DELGADO; PAUMGARTTEN, 2004).

No presente estudo, foram encontrados, por meio do exame físico: alterações de sensibilidade em membros inferiores (47,8\%), sensibilidade em membros superiores (41,3\%), redução de força muscular em membros inferiores (17,3\%) e em membros superiores $(15,2 \%)$, redução do campo visual (17,3\%), alterações de reflexos (13\%), alterações da coordenação de membros superiores $(10,8 \%)$ e membros inferiores $(6,5 \%)$, tremor $(10,8 \%)$, sinais radiculares $(6,5 \%)$, alterações da marcha $(6,5 \%)$, alterações do tônus em membros inferiores (2\%) e membros superiores (2\%) e presença de tiques (2\%).

Dois casos de polineuropatia tardia induzida por organofosforado foram diagnosticados a partir da avaliação neurológica e da correlação com a exposição no trabalho. Ambos adultos jovens, com idade entre 30 a 40 anos, com mais de 20 anos de exposição aos organofosforados e carbamatos na fumicultura e com história de intoxicação aguda anterior.

\section{Pesquisa dos transtornos psiquiátri- cos menores}

Para a identificação de transtornos psiquiátricos menores, utilizou-se o SRQ-20. O ponto de corte foi de $7 / 8$ (até 7 respostas positivas $=$ não caso $; 8$ ou mais respostas positivas = caso) para ambos os sexos.

Dos trabalhadores investigados, 18 apresentaram SRQ-20 positivo, o que perfaz $39 \%$ da amostra. Em estudo realizado no Rio Grande do Sul, com agricultores familiares expostos a múltiplos agrotóxicos, a prevalência encontrada foi de $41 \%$ no município de Antônio Prado e 32\% no município de Ipê (FARIA ET AL., 2000), resultados similares aos encontrados na presente pesquisa. 


\section{Exames laboratoriais}

Os resultados dos exames laboratoriais de 12 participantes se apresentaram alterados para aminotransferase de alanina (ALT), aminotransferase de aspartate (AST), gama glutamil transaminases (GGT), fosfatase alcalina (FA) e bilirrubinas totais (BT). Dois trabalhadores apresentaram ALT e AST alterados, e um apresentou AST e GGT alterados. Os demais exames apresentaram resultados dentro dos parâmetros da normalidade, inclusive os de colinesterases.

Os exames de colinesterase plasmática e eritrocitária não demonstraram resultados diferentes dos valores observados na população em geral. Isso é explicado, em parte, porque $40 \%$ dos participantes já não mais trabalhavam com fumicultura na ocasião da pesquisa. Contribuiu também para que os níveis de colinesterase se encontrassem dentro dos limites da normalidade o fato de que as amostras foram coletadas no período entre o processo de capação (retirada manual dos botões florais) e o início da colheita do fumo, nos quais não se faz uso de inibidores de colinesterases.

Os exames de colinesterases eritrocitária e plasmática são descritos como indicadores biológicos de exposição aos agrotóxicos organofosforados e carbamatos pela Norma Regulamentadora $\mathrm{n}^{0} 7$ do Ministério do Trabalho, sendo muito utilizados, ainda hoje, como único controle de intoxicações, principalmente em campanhas promovidas por entidades patronais. Diversos estudos, no entanto, já indicaram a limitação desse tipo de controle (KAMANYIRE; KARALLIEDDE, 2004; FARIA; ROSA; FACCHINI, 2009), que, primeiramente, necessitaria da determinação da atividade da enzima pré-ocupacional, para posterior comparação. Além disso, a enzima sofre inibição por diversas outras causas, tais como: fatores genéticos, idade, sexo, gravidez, agentes terapêuticos, desnutrição e outras doenças. O acompanhamento ou a avaliação da saúde desses trabalhadores não deve, portanto, restringir-se à dosagem de colinesterases. $O$ indicado seria a realização de avaliação clínica, exame físico e pesquisa do histórico ocupacional e de exposição aos produtos tóxicos ao longo dos anos de trabalho (PARANÁ, 2013).

\section{Avaliação audiológica}

No que se refere aos efeitos dos agrotóxicos no sistema auditivo, sabe-se que grande parte dos agrotóxicos utilizados na agricultura é neurotóxica e que, além de ocasionar problemas mais sérios na saúde humana, pode afetar o sistema auditivo central e periférico, sobretudo os organofosforados (JOHNSON; MORATA, 2010). Há indícios de que a perda auditiva seja uma manifestação precoce da intoxicação (AZEVEDO, 2004).

Tabela 1. Resultado da avaliação audiológica básica (audiometria e curva timpanométrica) de acordo com a orelha. Rio Azul, 2000 a 2010

\begin{tabular}{|c|c|c|c|c|}
\hline \multirow[t]{2}{*}{ RESULTADOS } & \multicolumn{2}{|c|}{ ORELHA DIREITA } & \multicolumn{2}{|c|}{ ORELHA ESQUERDA } \\
\hline & n & Percentual (\%) & $\mathrm{N}$ & Percentual (\%) \\
\hline \multicolumn{5}{|l|}{ Audiometria } \\
\hline Alterado & Normal & 34,78 & 18 & 39,14 \\
\hline 16 & 30 & 65,21 & 28 & 60,86 \\
\hline TOTAL audiometria & 46 & 100 & 46 & 100 \\
\hline
\end{tabular}


Tabela 1. (cont.)

\begin{tabular}{|c|c|c|c|c|}
\hline \multicolumn{5}{|l|}{ Curva timpanométrica } \\
\hline A & 35 & 76,08 & 39 & 84,78 \\
\hline $\mathrm{Ad}$ & 3 & 6,52 & - & 0,00 \\
\hline As & 2 & 4,34 & 2 & 4,34 \\
\hline B & 1 & 2,17 & 1 & 2,17 \\
\hline C & 1 & 2,17 & - & 0,00 \\
\hline Sem resposta & 4 & 8,69 & 4 & 8,69 \\
\hline TOTAL curva timpanométrica & 46 & 100 & 46 & 100 \\
\hline
\end{tabular}

Fonte: Elaboração própria.

A: mobilidade normal do sistema tímpano-ossicular; Ad: hipermobilidade do sistema tímpano-ossicular; As: baixa mobilidade do sistema tímpanoossicular; B: ausência de mobilidade do sistema tímpano-ossicular; C: pressão de ar da orelha média desviada para pressão negativa.

Neste estudo, a avaliação audiológica básica dos 46 participantes demonstrou alteração em $34,78 \%$ na orelha direita e $39,14 \%$ na orelha esquerda. A maioria das alterações foi do tipo neurosensorial (58,00\%), afetando, principalmente, as altas frequências. Quanto à curva timpanométrica, a maior parte dos participantes apresentou curva timpanométrica do tipo A, o que demonstra integridade de orelha externa e média. Esses resultados encontram-se compatíveis com os estudos que demonstraram associação entre a exposição a agrotóxicos e a alteração nos limiares auditivos de agricultores (JOHNSON; MORATA, 2010; LOBATO, 2015).

É comum a disfunção auditiva causada por agrotóxicos ser uma perda auditiva neurosensorial, sendo as frequências altas as mais afetadas na audiometria tonal liminar (3 a $6 \mathrm{kHz}$ ) e na audiometria de altas frequências, as frequências de 9.000 e $11.200 \mathrm{~Hz}$. A exposição aos agrotóxicos poderá estar associada à ausência de reflexo acústico, à redução da relação sinal/ruído das EOA e à disfunção do sistema auditivo eferente olivococlear (LOBATO, 2015).

Tabela 2. Resultado das EOAT e Peate de acordo com a orelha. Rio Azul, 2000 a 2010

\begin{tabular}{|c|c|c|c|c|}
\hline \multirow[t]{2}{*}{ RESULTADOS } & \multicolumn{2}{|c|}{ ORELHA DIREITA } & \multicolumn{2}{|c|}{ ORELHA ESQUERDA } \\
\hline & $\mathbf{n}$ & Percentual (\%) & $\mathbf{N}$ & Percentual (\%) \\
\hline \multicolumn{5}{|l|}{ EOAT } \\
\hline Alterado & 07 & 43.75 & 07 & 43.75 \\
\hline Normal & 09 & 56,25 & 09 & 56,25 \\
\hline TOTAL EOAT & 16 & 100 & 16 & 100 \\
\hline \multicolumn{5}{|l|}{ Peat } \\
\hline Alterado & 04 & 66.66 & 03 & 50,00 \\
\hline Normal & 02 & 33.33 & 03 & 50,00 \\
\hline TOTAL Peate & 06 & 100 & 06 & 100 \\
\hline
\end{tabular}

Fonte: Elaboração própria. 
Os dados da tabela 2 demonstram alteração coclear, identificada por meio das EOAT, e alteração retrococlear, identificada por meio do Peate. A alteração coclear está relacionada com alteração no sistema auditivo periférico, e a alteração retrococlear está relacionada com alterações no sistema auditivo central. Ambas podem trazer consequências para a vida cotidiana e necessitam de ações de prevenção.

Com relação aos resultados do RGDT, dos 20 participantes avaliados, nove apresentaram alteração no exame (45\%), e 11 apresentaram resultados normais (55\%). Demonstra-se, com esses dados, a presença de alteração na habilidade auditiva temporal. As alterações nas habilidades temporais geram dificuldades na percepção de estímulos que se modificam rapidamente, o que pode afetar a discriminação e o processamento fonológico do som da língua e interferir na compreensão de fala.

Os resultados audiológicos do presente estudo (tabelas 1 e 2 e do RGDT) encontram-se compatíveis com os estudos que demonstraram associação entre a exposição a agrotóxicos e a alteração nos achados auditivos periféricos e centrais de agricultores. Isso reafirma a necessidade do monitoramento audiológico (por meio das avaliações básica e complementar) para a vigilância à saúde das populações expostas a tais venenos (LOBATO, 2015).

\section{Estabelecimento do diagnóstico de intoxicação crônica por agro- tóxico decorrente de atividade da fumicultura}

Estudadas as relações entre dados colhidos nas diferentes etapas, dos 46 adultos avaliados, 20 tiveram firmado o diagnóstico de intoxicação crônica por agrotóxicos.

As três manifestações mais comuns nas intoxicações crônicas por exposição a múltiplos agrotóxicos encontradas foram: transtornos psiquiátricos menores (90\%), perda auditiva neurosensorial (15\%) e polineuropatia tardia induzida por organofosforados (10\%). Os casos de perda auditiva neurosensorial foram investigados por meio da avaliação básica e complementar.

Outra relação que se mostrou significativa $(p=0,0048)$ foi entre a intoxicação crônica e a história de intoxicação aguda no passado, através do teste Qui-quadrado, com nível de significância de 0,05 (5\%).

Todos os participantes receberam o laudo da sua avaliação, juntamente com os resultados dos exames laboratoriais e audiológicos, e os 20 casos de intoxicação crônica foram notificados no Sinan.

\section{Considerações finais}

Os fumicultores do grupo estudado são pequenos proprietários de terra, de pouca escolaridade, com dificuldades de acesso a financiamento, transporte, serviços básicos de saneamento e saúde, e um terço deles obtém uma renda que é insuficiente para a manutenção da própria sobrevivência e de sua família.

O Sistema Integrado, embora garanta a compra do tabaco produzido pelo agricultor, impõe a utilização de um pacote tecnológico, como sementes e agrotóxicos, um processo de trabalho pré-determinado e pouca autonomia para classificar e vender seu produto pelo melhor preço.

Esse modo de vida e o trabalho impactam diretamente a saúde desses agricultores. A exposição continuada a agrotóxicos na fumicultura em Rio Azul tem determinado intoxicações crônicas identificadas, no presente estudo, pelos transtornos psiquiátricos menores, pela perda auditiva e pela polineuropatia tardia induzida por organofosforados.

A alta frequência dos processos mórbidos experimentados pelos fumicultores se deve, no âmbito individual, ao contato com múltiplos agentes tóxicos, associado ao esforço 
físico intenso, realizado em extensas jornadas de trabalho mal remunerado. Tais condições de vida expressam uma inserção precária nos espaços da produção e do consumo, característica do modo de vida particular que lhes é imposto. Em última instância, seu adoecimento e sua precariedade na realização da vida

\section{Referências}

ALMEIDA, G. E. G. Fumo: servidão moderna e violações de direitos humanos. Curitiba: Terra de Direitos, 2005.

ARAUJO, A. J. et al. Exposição múltipla a agrotóxicos e efeitos à saúde: estudo transversal em amostra de 102 trabalhadores rurais, Nova Friburgo, RJ. Ciência \& Saúde Coletiva, Rio de Janeiro, v. 12, n. 1, p. 115-130, mar. 2007. Disponível em: <http://www. scielo.br/scielo.php?script=sci_arttext\&pid=S1413$-81232007000100015 \& \operatorname{lng}=e n \& n r m=i s o>$. Acesso em: 9 ago. 2016.

AZEVEDO, A. P. M. Efeito de produtos químicos e ruído na gênese de perda auditiva ocupacional. 2004. 162 f. Dissertação (Mestrado Saúde Pública) - Escola Nacional de Saúde Pública, Fundação Oswaldo Cruz, Rio de Janeiro, 2004.

BASSIL, K. L. et al. Cancer health effects of pesticides: Systematic review. 2007. Can Fam Physician, v. 53 n. 10, p. 1704 -1711, 2007. Disponível em: <http://www.cfp.ca/ content/53/10/1704.long>. Acesso em: 8 dez. 2016.

BIOLCHI, M. A. A cadeia produtiva do Fumo. Revista Contexto Rural, Curitiba, v. 3, n. 4, 2003. Disponível em: $<$ http://www.deser.org.br/pub_read.asp?id=85>. Acesso em: 10 jul. 2016 advêm da lógica da produção de mais-valor, acima de tudo, necessidade precípua da sociedade capitalista. O combate ao adoecimento e a defesa da saúde desses, como de todos os trabalhadores, impõem, como objetivo final, a superação de tal modo de produção por outro que priorize a vida.
BONATO, A. Conjuntura: Fumo: a fumicultura e a convenção-quadro, desafios para a diversificação. Curitiba: Deser, 2009. Disponível em: <www.deser.org.br/pub_ download.asp?href=publicacoes/Fumo.zip\&id=146>. Acesso em: 9 jul. 2016.

BONATO, A.; ZOTTI, C. F.; ANGELIS, T. Tabaco: da produção ao consumo: uma cadeia da dependência. Curitiba: Deser, 2010.

BRASIL. Ministério da Saúde. Datasus, Tecnologia da Informação a serviço do SUS: Intoxicação exógena - notificações registradas no sinan net - Paraná. Disponível em: <http://tabnet.datasus.gov.br/cgi/deftohtm.exe?sinannet/cnv/Intoxpr.def $>$. Acesso em: 20 jul. 2016.

BREILH, J. Epidemiologia crítica: ciência emancipadora e interculturalidade. Rio de Janeiro: Fiocruz, 2006.

DELGADO, I. F.; PAUMGARTTEN, F. J. R.

Intoxicações e uso de pesticidas por agricultores do município de Paty do Alferes, Rio de Janeiro, Brasil. Cad. Saúde Pública, Rio de Janeiro, v. 20, n. 1, p. 180-186, jan./fev. 2004.

DEPARTAMENTO DE ESTUDOS SÓCIO-

ECONÔMICOS RURAIS (DESER). Boletim eletrônico, 
Curitiba, n. 2, out. 2012. Disponível em: <http://www. deser.org.br/adm/ver.asp?id=56>. Acesso em: 8 set. 2016.

FALK, J. W. et al. Suicídio e doença mental em Venâncio Ayres - RS: conseqüência do uso de agrotóxicos organofosforados? Relatório Preliminar de Pesquisa. UFRGS, Porto Alegre, 1996. Disponível em: <http:// mpt-prt09.jusbrasil.com.br/ noticias/1383672/mpt-ajuiza-acoes-para-condenar-industrias-fumageiras-a-indenizar-fumicultore >. Acesso em: 15 jul. 2016.

FARIA, N. M. X.; ROSA, J. A. R.; FACCHINI, L. A. Intoxicações por agrotóxicos entre trabalhadores rurais de fruticultura, Bento Gonçalves, RS. Rev. Saúde Públ., São Paulo, v. 43, n. 2, p. 335-344, abr. 2009. Disponível em: <http://www.scielo. br/scielo.php?script=sci_arttext\&pid=S0034$-89102009000200015 \& \operatorname{lng}=$ pt\&nrm=iso $>$. Acesso em: 9 ago. 2016.

FARIA, N. M. X. et al. Processo de produção rural e saúde na serra gaúcha: um estudo descritivo. Cad. Saúde Pública, Rio de Janeiro, v. 16, n. 1, p. 115-128, 2000. Disponível em: <http://www.scielo.br/scielo. php?script=sci_arttext $\&$ pid $=$ S0102-311X200000010001 $2 \& \operatorname{lng}=$ en\&nrm=iso $>$. Acesso em: 8 ago. 2016.

HU, R. et al. Long - and Short - Term Health Effects of Pesticide Exposure: A Cohort Study from China. PLoS ONE, v. 10, n. 6, 2015. Disponível em: <http://doi. org/10.1371/journal.pone>. Acesso em: 7 dez. 2016.

\section{INSTITUTO BRASILEIRO DE GEOGRAFIA E}

ESTATÍSTICA (IBGE). Previsão e acompanhamento de safras: uso de agrotóxicos no estado do Paraná. Safra 1998/1999. Rio de Janeiro: IBGE, 2001. Disponível em: $<$ http://biblioteca.ibge.gov.br/visualizacao/livros/ liv7308.pdf >. Acesso em: 21 jul. 2016.

Pesquisa Nacional por Amostra de Domicílios.

Pesquisa Básica - 2001 a 2013. 2013. Disponível em: <http://www.sidra.ibge.gov.br/pnad/pnadpb.asp>. Acesso em: 20 jul. 2016.

JOHNSON, A. C.; MORATA, T. C. Occupational exposure to chemicals and hearing impairment. Arbet $\mathrm{OCH}$
Halsa, Gothenburg-Sweden, v. 44, n. 4, p. 1-177, 2010.

JUSBRASIL. MPT ajuiza ações para condenar indústrias fumageiras a indenizar fumicultores. Curitiba, 2007. Disponível em: <https://mpt-prt09.jusbrasil.com. br/noticias/1383672/mpt-ajuiza-acoes-para-condenar-industrias-fumageiras-a-indenizar-fumicultores>. Acesso em: 18 jul. 2016.

LOBATO, D. C. B. Disfunção auditiva induzida por agrotóxicos em trabalhadores agrícolas do Paraná. 2015. 132 f. Tese (Doutorado em Distúrbios da Comunicação) - Universidade Tuiuti do Paraná, Curitiba, 2015.

KAMANYIRE, R.; KARALLIEDDE, L.

Organophosphate toxicity and occupational exposure. Occupational Medicine. Occupational Medicine, v. 54, n. 2, p. 69-75, 2004. Disponível em: <http://occmed. oxfordjournals.org/content/54/2/69.full.pdf+html . Acesso em: 4 ago. 2016.

KAMEL, F.; HOPPIN, J. A. Association of Pesticide Exposure with Neurologic Dysfunction and Disease. Environmental Health Perspectives, Research Triangle Park, v. 112, n. 9, p. 950-958, 2004. Disponível em: <http://doi.org/10.1289/ehp.7135>. Acesso em: 7 dez. 2016.

MARI, J. J.; WILLIAMS, P. A validity study of a psychiatric screening questionnaire 1. (SRQ-20) in primary care in the city of São Paulo. Br. J. Psychiatry, Londres, v. 148, p. 23-6, 1986.

MARX, K. O capital: crítica da economia política. São Paulo: Boitempo, 2013. (livro I).

MATOS, G. B.; SANTANA, O. A. M.; NOBRE, L. C. C. Intoxicação por agrotóxicos. In: BAHIA. Secretaria da Saúde do Estado. Manual de Normas e Procedimentos Técnicos para a Vigilância da Saúde do Trabalhador. Salvador: Secretaria de Saúde do Estado da Bahia; 2002.

ORGANIZAÇÃO PAN-AMERICANA DE SAÚDE/ ORGANIZAÇÃO MUNDIAL DA SAÚDE (OPAS/

OMS). Manual de vigilância da saúde de populações expostas a agrotóxicos. Brasília, DF: Organização 
Pan-Americana de Saúde/Organização Mundial da Saúde, 1996.

PACHECO-FERREIRA, H. Epidemiologia das substâncias químicas neurotóxicas. In: MEDRONHO, R. A. et al. (Org.). Epidemiologia. São Paulo: Atheneu, 2008. p. $577-86$

PARANÁ. Agrotóxicos no Paraná: faça sua pesquisa. Disponível em: <http://celepar07web.pr.gov.br/agrotoxicos/pesquisar.asp>. Acesso em: 20 jul. 2016a.

Análise da conjuntura agropecuária: fumo - Safra 2015/16. Disponível em: <http://www.agricultura. pr.gov.br/arquivos/File/deral/Prognosticos/2016/ fumo_2015_16.pdf>. Acesso em: 22 jun. 2016b.

Secretaria de Estado da Saúde. Superintendência de Vigilância em Saúde. Centro Estadual de Saúde do Trabalhador. Protocolo de avaliação das intoxicações crônicas por agrotóxicos. Curitiba: Sesa, fev. 2013. Disponível em: <http://www. saude.pr.gov.br/arquivos/File/CEST/Protocolo_ AvaliacaoIntoxicacaoAgrotoxicos.pdf $>$. Acesso em: 29 maio 2017.

RIGON, S. A.; BEZERRA, I. Segurança alimentar e nutricional, agricultura familiar e compras institucionais: desafios e potencialidades. Demetra: alimentação, nutrição e saúde, v. 9, n. 2, 2014. Disponível em: <http:// www.epublicacoes.uerj.br/index.php/demetra/article/ view/11628\#.VHhZvNLF_Z0>. Acesso em: 28 nov. 2014.

RIGOTTO, R. M. et al. Tendências de agravos crônicos à saúde associados a agrotóxicos em região de fruticultura no Ceará, Brasil. 2013. Rev. bras. epidemiol., São Paulo, v. 16, n. 3, p. 763-773, 2013. Disponível em: $<$ http://www.scielosp.org/scielo.php?script=sci arttext\&pid=S1415-790X2013000300763\&lng=en\&nrm =iso>. Acesso em: 5 dez. 2016.

Recebido para publicação em agosto de 2016

Versão final em março de 2017

Conflito de interesses: inexistente

Suporte financeiro: Programa de Pesquisa para o SUS (PP-SUS), via Fundação Araucária/UFPR, Projeto financiado pela chamada 09/2009, Código do SISCT: EFP_00002785, Protocolo № 19490 